\title{
Increasing ADR reporting in Nepal
}

\author{
Shankar P R ${ }^{1}$
}

1Professor, Xavier University School of Medicine, Aruba, Dutch Caribbean

Chief Editor

Dr. Indrajit Banerjee

Grammar Editor

Dr. Nishida Chandrasekharan

\section{Letter to the Editor}

\section{Corresponding Author:}

Dr. P Ravi Shankar MD

Xavier University School of Medicine

Aruba, Dutch Caribbean

E-mail: ravi.dr.shankar@gmail.com

Dear Editor,

I read with great interest the article by Santosh KC and coauthors titled 'Strengthening the pharmacovigilance programme in Nepal'

I agree with the authors that more regional centres should be started. A problem however may be that due to a variety of reasons many centres are not functioning optimally. I also agree that knowledge about pharmacovigilance and its importance is poor even among pharmacologists and pharmacists. Under reporting remains a problem and a previous study conducted at KIST Medical College had examined adverse drug reactions (ADRs) submitted to the centre and possible steps to improve reporting rates ${ }^{2}$. Communication between the centres and the reporters remains a problem. Reporters are not able to benefit from the ADR reports and hence consider reporting as something to be avoided. Community pharmacies can play an important role in ADR reporting due to their number and reach and should be specifically targeted.

With increasing education and rising socioeconomic status ADR reporting by consumers can supplement reporting by professionals ${ }^{3}$. In many countries the pharmaceutical industry plays an important role in pharmacovigilance ${ }^{4}$. In Nepal it is not mandatory for the industry to report ADRs and few reports are received from the industry. The issue of which organization should take the lead with regard to pharmacovigilance in the country has been recently discussed ${ }^{5}$.

Not all publications relating to pharmacovigilance in the country have been highlighted in the manuscript. The criteria which the authors followed for selecting and citing references can be explained. Strengthening pharmacovigilance in Nepal is an essential but daunting task with tremendous implications for patient safety and rational use of medicines.

\section{References}

1. Santosh KC, Tragulpiankit P, Gorsanan P, Edwards IR, Alam K. Strengthening the pharmacovigilance programme of Nepal. Nepal Journal of Epidemiology 2013;3(1):230-235. 2. Jha N, Shankar PR, Bajracharya O, Gurung SB, Singh KK. Adverse drug reaction reporting in a pharmacovigilance centre of Nepal. Australas Med J 2012;5:268-71.

3. Fernandopulle RB, Weerasuriya K. What can consumer adverse drug reaction reporting add to existing health professional-based systems? Focus on the developing world. Drug Saf 2003;26(4):219-25.

4. Gibson $B R$, Suh R, Tilson $H$. The US drug safety system: role of the pharmaceutical industry. Pharmacoepidemiol Drug Saf 2008;17(2):110-4.

5. Shankar PR. Pharmacovigilance in Nepal: Whose baby is it anyway? Australas Med J 2013:6:132-133.

\begin{tabular}{|l|l|}
\hline \multicolumn{2}{|c|}{ Article Information } \\
\hline \multicolumn{2}{|c|}{ Article history } \\
\hline Received & 16 June 2013 \\
\hline Received in revised form & 18 June 2013 \\
\hline Accepted & 19 June 2013 \\
\hline
\end{tabular}

